\title{
NEUE
}

Heft 2/Mai 1992
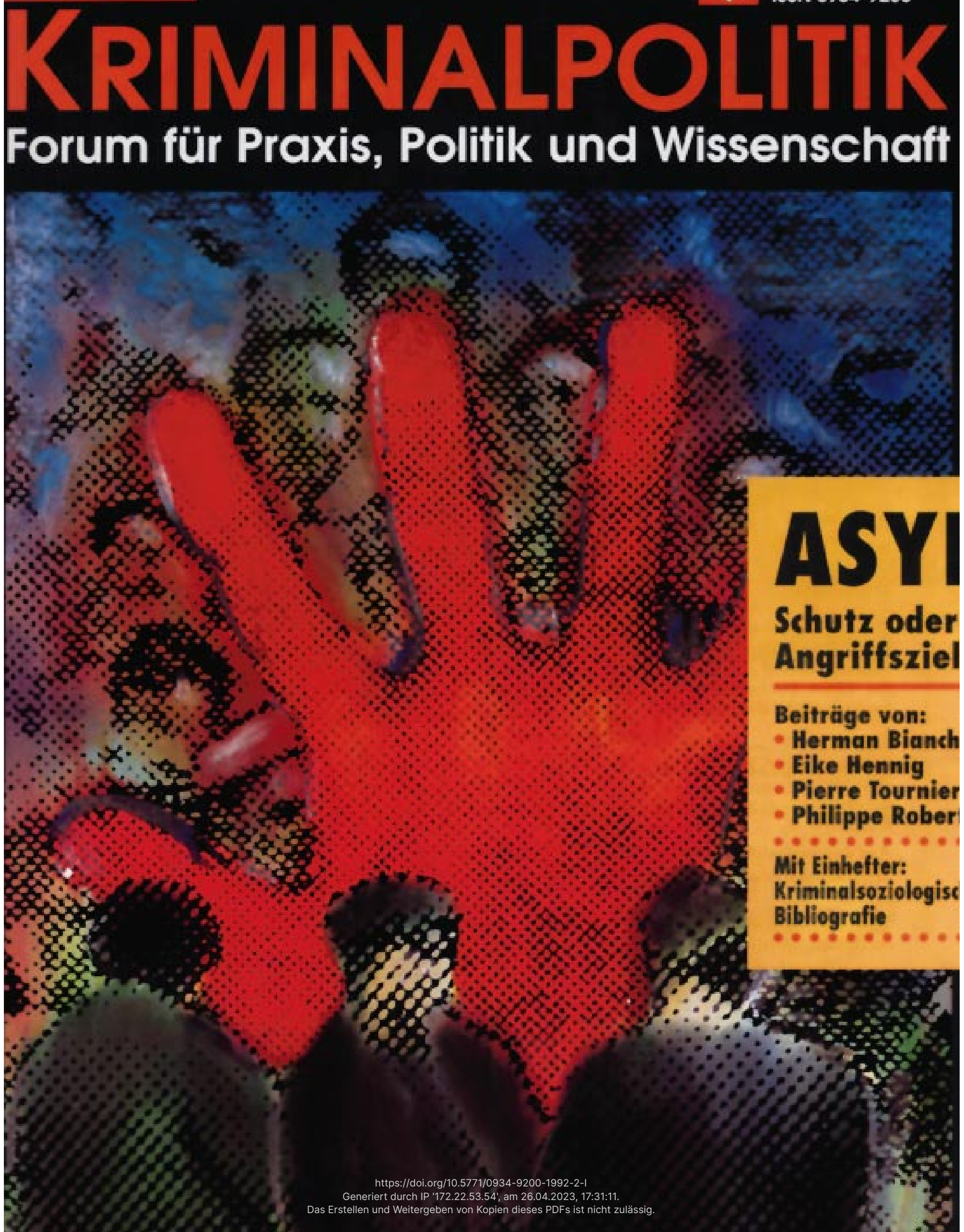


\section{Liebe Leserin, lieber Leser!}

$\mathrm{E}$ xportartikel Neue Kriminalpolitik: An Abonnenten in 14 Ländern wird unsere Zeitschrift bislang geliefert. Zur Topographie unserer Leserschaft gehören Leser in Rondebosch/Südafrika, im argentinischen Buenos Aires, und in Fukuoka/ Japan. Die meisten Auslands-Hefte gehen nach Österreich - über 200 -, die wenigsten - zwei nach Finnland.

$\mathrm{I}^{\mathrm{n}}$ nformationsquelle Neue Kriminalpolitik: Unser Interview mit Mecklenburgs Justizminister Ulrich Born (NK 1-92), in dem er sich über mangelnde Hilfe des Westens beim Aufbau der Justiz in den neuen Bundesländern beklagte, fand große Aufmerksamkeit. Mehrere Redaktionen baten um das druckfrische Heft, die FRANKFURTER RUNDSCHAU berichtete über das Interview gar auf ihrer ersten Seite und vergaß dabei auch nicht - wie viele andere - die Quelle zu zitieren: Neue Kriminalpolitik. Mittlerweile hat die Tagespolitik Ulrich Born auf das Abstellgleis verbannt. Nach dem Rücktritt seines Ministerpräsidenten Gomolka war auch für den aufmüpfigen Justizminister kein Platz mehr im Kabinett. Born mußte gehen, die Probleme der mecklenburgischen Justiz bleiben.

$\mathrm{T}$ itel-Thema in Neue Kriminalpolitik: die Asyldebatte. Allerorten: Ausländerfeindliche Dramatisierungen und bürokratische Gleichgültigkeit.

Höchste Zeit also sich einzumischen. Vier namhafte Autoren - der Niederländer Herman Bianchi, der Deutsche Eike Hennig, die beiden Franzosen Pierre Topurnier und Philippe Robert schreiben in diesem Heft gegen und über die Ruinierung des Asylgedankens. Die Österreicher Arno Pilgram und Heinz Steinert - beide MitHerausgeber dieser Zeitschrift - in ihrer Einleitung ,Kriminalpolitisch Interessierte sind aus besonderen Gründen sensibilisiert für Debatten um die Institution des Asyls. Denn: Das Asyl als Schutzraum für politisch und religiös Abweichende und Verfolgte ist auch ein Korrektiv für Strafunrechtssysteme."

Zweierlei - das zeigen unsere Autoren - ist not-

wendig: „Schutz durch das Recht“ und „Schutz vor dem Recht“". Unser Titel-Thema ab Seite 28.

$\mathrm{K}$ öpfe in Neue Kriminalpolitik: Daß wir gerne Köpfe in unserer Zeitschrift zeigen, Menschen, die im Bereich der Kriminalpolitik VorDenker und Vor-Macher sind, wissen unsere Leserinnen und Leser. Viele, u.a. Helga Einsele, Heinrich Hannover, Horst Schüler-Springorum, Gerhard Mauz, Jean Ziegler, Hermann Möller, zuletzt Lieselotte Pongratz, haben wir bisher vorgestellt.

Diesmal porträtieren wir einen Mann, der seit Jahren auch hierzulande als produktiver kriminalpolitischer Querdenker gilt: Thomas Mathiesen, Professor für Rechtssoziologie. Knut Papendorf hat ihn in Oslo besucht. Sein Porträt auf Seite 44.

Dremiere in nalpolitik: In der Heftmitte finden Sie erstmals den Einhefter Kriminalsoziologische Bibliografie. Aufsätze in- und ausländischer Zeitschriften sind hier nach Sachthemen bibliographiert.

Ein zusätzlicher Nutz- und Gebrauchswert für unsere Abonnenten - und das von

KRIMINALSOZOLOGISCHE BIBUOGRAFE

nun an in jedem zweiten Heft. Und damit Sie zukünftig rasch und gezielt nachschlagen können, haben wir einen KB-Sammelordner in Auftrag gegeben. Mehr dazu im nächsten Heft.

Ich bin sicher, auch die anderen Beiträge finden Ihr Interesse. In diesem Sinne wünsche ich beste Fachlektüre

\section{Ihr Helmut Ortner}


Asyl: Schutz oder Angriffsziel?

Die aktuelle A syl-Debatte ist geprägt von populistischen ausländerfeindlichen Dramatisierungen und bürokratischer $G$ leichgültigkeit. $G$ egen und über die Ruinierung des A sylgedankens schreiben unsere A utoren.

Titel-Thema ab Seite 28

\section{„Resignation lasse ich nicht gelten ...."}

Die Drogensyndikate "waschen"ihr

"dreckiges" G eld. Die

Banken spielen mit, die Bundesregierung hält sich mit ihrem G esetzentw urf zurück. Kritische Äußerungen des Frankfurter 0 berstaatsanwalts Harald Hans Körner in unserem Interview

ab Seite 18

Blick zurück in
die Zukunft

Im Jahr 2077: Einhundert Jahre nach

Inkrafttreten des Strafvollzugsgesetzes zieht ein Rechtshistoriker Bilanz. Einhundert Jahre Strafvollzugsgeschichte. Ein A usblick von

Sebastian Scheerer ab Seite 20

\section{Der Neugierige}

Seine "Strategie der Negation" hat nicht nur in ihrer theoretischen Konzeption, sondern auch in ihrer praktischen Konseqenz in vielen Ländern A nerkennung gefunden: Thomas Mathiesen, Professor für Rechtssoziologie an der Universität 0 slo. Ein Porträt ab Seite 44
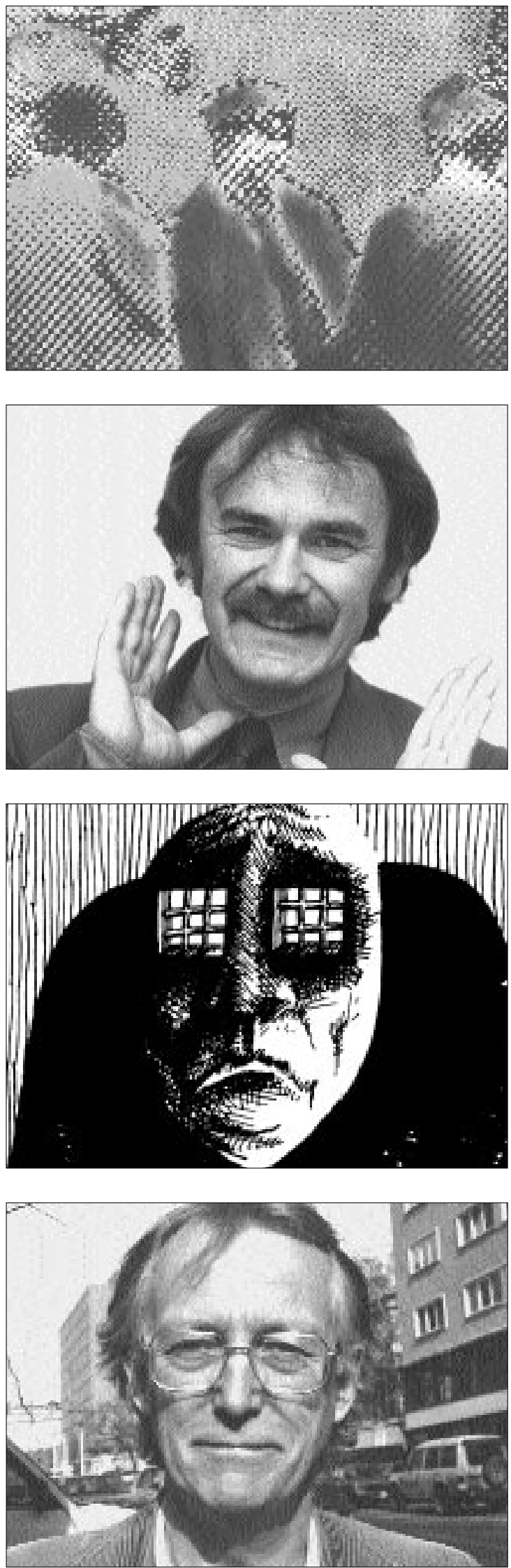

TITEL

\section{Asyl: Schutz oder Angriffsziel?}

Von der Freistatt zum Recht Herman Bianchi

A usländerfeindlichkeit: Ein Produkt von Wohlstandschauvinismus und $\mathrm{N}$ ationalismus? Eike Hennig

Mehr $\mathrm{G}$ efangene als Täter

Pierre Tournier und Philippe Robert

\section{MAGAZIN}

Jugendstrafvollzugsgeset: Maßstab Mann 8 - A rrest für Schulschwänzer: Klassenzimmer oder Knast? 9 • Strafvollzug: Ausreichende Aids-Prävention? 10 • $N$ iederlande: A nonymer Rechtsstaat? 14 • Ö sterreich: N ur Lippenbekenntnisse $\mathbf{1 5}$ - England: Private $\mathrm{G}$ efängnisse 16

\section{INTERVIEW}

»Resignation lasse ich nicht gelten ... « Constanze Kleis sprach mit dem Frankfurter O berstaatsanwalt Harald Hans Körner

BEITRAG

Blick zurück in die Zukunft

Sebastian Scheerer

Strafrecht und Familienpolitik

Christa Pelikan

\section{MEINUNG}

Recht auf Sucht

Helmut O rtner

PORTRAIT

Der N eugierige - Thomas Mathiesen

Ein Portrait von Knut Papendorf

\section{RUBRIKEN}

Editorial

Compakt

Zur Person

Praxis

41

Terminal

46

Bücher

Vorschau

48

Impressum

50

50

Beilagenhinweis: Dieser Ausgabe liegt ein Prospekt der Nomos Verlagsgesellschaft bei. Wir bitten freundlichst um Beachtung. 